\title{
Alpha2-Adrenergic-Agonist Brimonidine Stimulates Negative Feedback and Attenuates Injury-Induced Phospho-ERK and Dedifferentiation of Chicken Müller Cells
}

\author{
Mohammad Harun-Or-Rashid, ${ }^{1}$ Marta Díaz-DelCastillo, ${ }^{1}$ Caridad Galindo-Romero, ${ }^{1,2}$ \\ and Finn Hallböök ${ }^{1}$
}

${ }^{1}$ Department of Neuroscience, Uppsala University, Uppsala, Sweden

${ }^{2}$ Departamento de Oftalmología, Facultad de Medicina, Universidad de Murcia, and Instituto Murciano de Investigación Biosanitaria Virgen de la Arrixaca (IMIB-Arrixaca), Murcia, Spain

Correspondence: Finn Hallböök, Department of Neuroscience, Uppsala University, Husargatan 3, Box 593

75124 Uppsala, Sweden;

Finn.Hallbook@neuro.uu.se.

Submitted: March 6, 2015

Accepted: August 10, 2015

Citation: Harun-Or-Rashid M, DíazDelCastillo M, Galindo-Romero C, Hallböök F. Alpha2-adrenergic-agonist brimonidine stimulates negative feedback and attenuates injury-induced phospho-ERK and dedifferentiation of chicken Müller cells. Invest Ophthalmol Vis Sci. 2015;56:5933-5945. DOI:10.1167/iovs.15-16816
Purpose. Retinal injury induces Müller cell dedifferentiation by activating extracellular signalregulated kinase (ERK) signaling. Stimulation of $\alpha 2$-adrenergic receptors protects against injury but also activates ERK in Müller cells. The purpose of this work was to study the effect of $\alpha 2$-adrenergic signaling on injury-induced ERK and Müller cell dedifferentiation. We tested the hypothesis that $\alpha 2$-stimulation triggers negative feedback regulation of the injury-induced ERK pathway that attenuates Müller cell dedifferentiation.

MethoDs. Chicken retina injured by N-methyl-D-aspartate and cultured primary Müller cells were stimulated by the $\alpha 2$-adrenergic agonist brimonidine. Immunostaining, quantitative RTPCR, and Western blot techniques in combination with receptor blockers were used for analysis of the cellular responses.

RESults. Alpha2-adrenergic receptor stimulation attenuated injury-induced ERK activation and dedifferentiation of Müller cells as seen by decreased phospho-ERK, expression of transitin, and retinal progenitor cell genes. The attenuation was concomitant with a synergistic upregulation of several negative ERK-signal feedback regulators including ERK-phosphatases, Raf1-, and growth factor receptor-binding proteins. The results were also seen in cultures of primary Müller cells.

Concuusıons. Alpha2-adrenergic signaling on Müller cells elicits an intracellular attenuation of the injury response that comprises negative ERK-signaling feedback leading to attenuated Müller cell dedifferentiation. The implications of this study are that adrenergic stress signals may directly modulate glial function in retina and that $\alpha 2$-adrenergic receptor pharmacology may be used to control glial injury response.

Keywords: retina, Müller cell, alpha2 adrenergic receptor, dedifferentiation, neuroprotection
$M$ üller cells express $\alpha 2$-adrenergic receptors (ADR) and stimulation of these receptors leads to a robust but transient activation of extracellular signal-regulated kinases (ERK) $1 / 2$ kinase signaling. ${ }^{1-3}$ The ERK1/2-activation on Müller cells is mediated by Src-kinase activity and includes transactivation of epidermal growth factor receptors (EGFR) on Müller cells. ${ }^{3}$ Activation of EGFR signaling, which use ERK1/2, has been shown to be both necessary and sufficient to regulate zebrafish Müller cell-dedifferentiation and proliferation after retinal injury. ${ }^{4}$ The data are consistent with the engagement of ERK signaling for Müller cell dedifferentiation and proliferation as shown by the effects of ERK inhibitors on Müller cells after excitotoxic injury to the chicken retina. ${ }^{5,6}$ Moreover, $\alpha 2$-ADR signaling during an injury has been shown to reduce the adverse impacts on retinal ganglion cell survival. ${ }^{7-10}$ The underlying mechanisms include modulation of N-methyl-Daspartate (NMDA) receptor signaling in retinal ganglion cells or promotion of trophic factor synthesis in Müller cells that contributes to increased neuronal survival. ${ }^{11-13}$ However, the mechanisms behind the neuroprotection are still not fully understood.

The studies of retinal responses to either injury or to $\alpha 2$ ADR stimulation, disclose a potential paradox. On one hand, injury-induced ERK1/2 drives a gliotic response and neuronal loss. ${ }^{5,6}$ On the other hand, $\alpha 2$-ADRs stimulate the same pathway and reduce neuronal loss. In this work, we have addressed this paradox and have studied the early ERK response after an excitotoxic injury with or without $\alpha 2-\mathrm{ADR}$ stimulation. We have pretreated chicken retina with the $\alpha 2$ ADR-agonist brimonidine and induced a retinal lesion by NMDA-injection. The results were intriguing in that the $\alpha 2$ ADR stimulation, which in itself triggers a robust ERK response, attenuated both the NMDA-induced ERK and gliotic response as well as the induction of retinal progenitor cell genes. The results suggested that brimonidine attenuate not only the ERK response but also Müller cell dedifferentiation in the injured retina. Based on these results we hypothesized that stimulation of $\alpha 2$-ADRs on Müller cells triggers a negative 
feedback regulation of the ERK pathway in Müller cells, which otherwise would have caused activation and dedifferentiation of the Müller cells. This was tested in vivo and in vitro on primary Müller cells in culture. The results showed that $\alpha 2$-ADRs induce genes that are directly involved in negative ERK feedback regulation.

\section{Materials ANd Methods}

\section{Animals and Injections}

The use of animals was in accordance to the recommendations in the guide for the care and use of laboratory animals of the ARVO Statement for the Use of Animals in Ophthalmic and Vision Research and was approved of by the local animal ethics committee in Uppsala. Fertilized White Leghorn chicken eggs were obtained from OVA Produktion AB (Västerås, Sweden) and incubated at $38^{\circ} \mathrm{C}$ in a humidified egg-incubator (Grumbach, Asslar, Germany). Embryonic day (E) 18 embryos were injected intraocularly in the dorsal quadrant of the eye using a Hamilton syringe (Bonaduz, Switzerland) with $27-\mathrm{G}$ needle supplied with a stopper. A hole was made in the eggshell, head pulled up with a bent glass rod and the right eye $(n>5)$ was injected through the amniotic membranes. Pretreatment with $10 \mu \mathrm{L}$ brimonidine tartrate (UK-14 304; $200 \mu \mathrm{g}$ ) or vehicle were injected 1 hour prior to injection of $20 \mu \mathrm{L}$ NMDA $(294 \mu \mathrm{g})$ or vehicle (saline solution, 0.15 M NaCl; Supplementary Table S1).

\section{Primary Müller Cell Cultures}

Primary Müller cells cultures were established as previously described. ${ }^{3}$ Twelve E14 retinas were dissected, dissociated, and cultured in Dulbecco's modified Eagle's medium with 10\% NCS, $2 \mathrm{mM}$ glutamine, $100 \mathrm{U} / \mathrm{mL}$ penicillin, and $100 \mathrm{mg} / \mathrm{mL}$ streptomycin at $37^{\circ} \mathrm{C}$ for up to 4 weeks. Media were changed three times a week. The cultures were ready to use when the cultures only contained Müller cells. The cell purity was assessed by $2 \mathrm{M} 6$ immunocytochemistry and found to be greater than $95 \% .^{3}$ Serum-starved primary Müller cells in culture were supplemented with brimonidine tartrate (300 $\mu \mathrm{M})$, EGF $(100 \mathrm{ng} / \mathrm{mL}), \mathrm{FGF} 2(200 \mathrm{ng} / \mathrm{mL})$, or the $\alpha 2-\mathrm{ADR}$ inhibitor yohimbine $(100 \mu \mathrm{M})$. Controls were vehicle.

\section{Immunohistochemistry and Microscopy}

Immunohistochemistry were performed as described previously. ${ }^{3}$ Ten-micrometer sections were cut through the center of the lens and the optic nerve head containing dorsal and ventral retina. Primary and secondary antibodies are listed in Supplementary Table S2. Micrographs were from the dorsal aspect of the central retina. The same setting of exposure time for micrographs for the experimental groups allowed for a semiquantitative comparison of transitin IR by analyzing the fluorescence mean intensity in a fixed region of interest (ROI), spanning the entire retina, using ImageJ software (http:// imagej.nih.gov/ij/; provided in the public domain by the National Institutes of Health, Bethesda, MD, USA). For cellcounting, five sections per eye from five different animals and treatment group were used.

\section{Quantitative Reverse Transcriptase-PCR (qRT-PCR)}

Total RNA was isolated with TRIzol (Invitrogen, Carlsbad, CA, USA) and qRT-PCR analysis (IQ SyBr Green Supermix and a C1000 Thermal Cycler; Bio-Rad, Hercules, CA, USA) was performed as previously described. ${ }^{14,15}$ Polymerase chain reaction efficiency, linearity, and specificity were checked.
The mRNA levels were normalized to $\beta$-actin. This method has been validated by testing for the most stable mRNA expression of TATA binding protein (TBP), $\beta$-actin, $\beta$-2-microglobulin, and glyceraldehyde-3-phosphate dehydrogenase. Primers are listed in Supplementary Table S3. Expression levels were calculated from cycle threshold $(\mathrm{Ct})$ and the $2^{-} \Delta \Delta^{\mathrm{Ct}}$ method. ${ }^{16}$

\section{Western Blot and Statistical Analyses}

The Western blot analysis was performed according to the manufacturer's instruction (Bio-Rad) and as previously described. ${ }^{3,17}$ Protein densitometry was performed using Image Lab 4.1 (Bio-Rad). Primary and secondary antibodies are listed in the Supplementary Table S2. GraphPad Prism 6 (GraphPad Software, La Jolla, CA, USA) was used for statistical analysis by 1-way ANOVA followed by Tukey's multiple comparison post hoc test, as indicated in the figure legends.

\section{Results}

\section{Attenuation of Injury-Induced ERK1/2 Activity by Brimonidine}

Pretreatment by injection of brimonidine or saline was done 1 hour prior to injection of the excitotoxin NMDA or saline into the right eye of E18 chickens in ovo. Phosphorylation of ERK1/ 2 in retina was analyzed after 2,24 , and 48 hours (Fig. 1A). The results were compared with untouched normal retina and vehicle-injected eyes (Figs. 1B, 1I-K).

Immunohistochemistry for the activated form of ERK1/2 (phospho-ERK1/2, P-ERK) in combination with the Müller cell marker 2M6 was used to identify Müller cells with active ERK signaling. Overlap between P-ERK and 2M6 immunoreactivity (IR) showed that Müller cells express P-ERK. Phospho-ERK1/2 IR was not exclusive to Müller cells. Equally low P-ERK IR was observed in retina from normal and vehicle-injected eyes (Figs. 1B, 1I-K). At 2 hours after NMDA injection, a weak but above control P-ERK IR was detected in $2 \mathrm{M} 6$ positive $(+)$ Müller cells in the retina (Figs. 1B, 1C, 1I). The P-ERK IR was high at 24 hours after NMDA injection (Fig. 1D) and weaker at 48 hours (Fig. 1E), but still higher than the control. The P-ERK pattern at 48 hours was uneven showing regions with strong IR mixed with weaker regions (Fig. 1E). The 2M6 IR appeared stronger in Müller cells in injured than in normal retina, which is consistent with data showing increased 2 M6 IR in chicken retina after optic nerve crush injury. ${ }^{18}$

Analysis of the effect of pretreatment with brimonidine 1 hour prior to the excitotoxic lesion showed increased P-ERK IR in injured, brimonidine pretreated injured and brimonidine treated noninjured retinas at the 2-hour time-point after injury. The IR was stronger in both the pretreated injured and the brimonidine-treated noninjured retina at 2 hours than in the injured retina without pretreatment (Figs. 1C, 1F, 1L). At 24 and 48 hours the relation was opposite, there was a lower P-ERK IR in the brimonidine pretreated injured retina than in the injured retina without pretreatment (Figs. $1 \mathrm{D}, 1 \mathrm{E}, 1 \mathrm{G}, 1 \mathrm{H})$, indicating an attenuation of ERK signaling by the pretreatment. The brimonidine-treated noninjured retina had low P-ERK IR that was similar to normal retina (Figs. 1M, 1N)

The result was confirmed by using Western blot analysis (Fig. 1O, Supplementary Fig. S1) and a densitometric analysis of the blots showed statistically supported differences between injured retinas with or without brimonidine pretreatment (Fig. 1N, Supplementary Fig. S1), compared with control. 
A
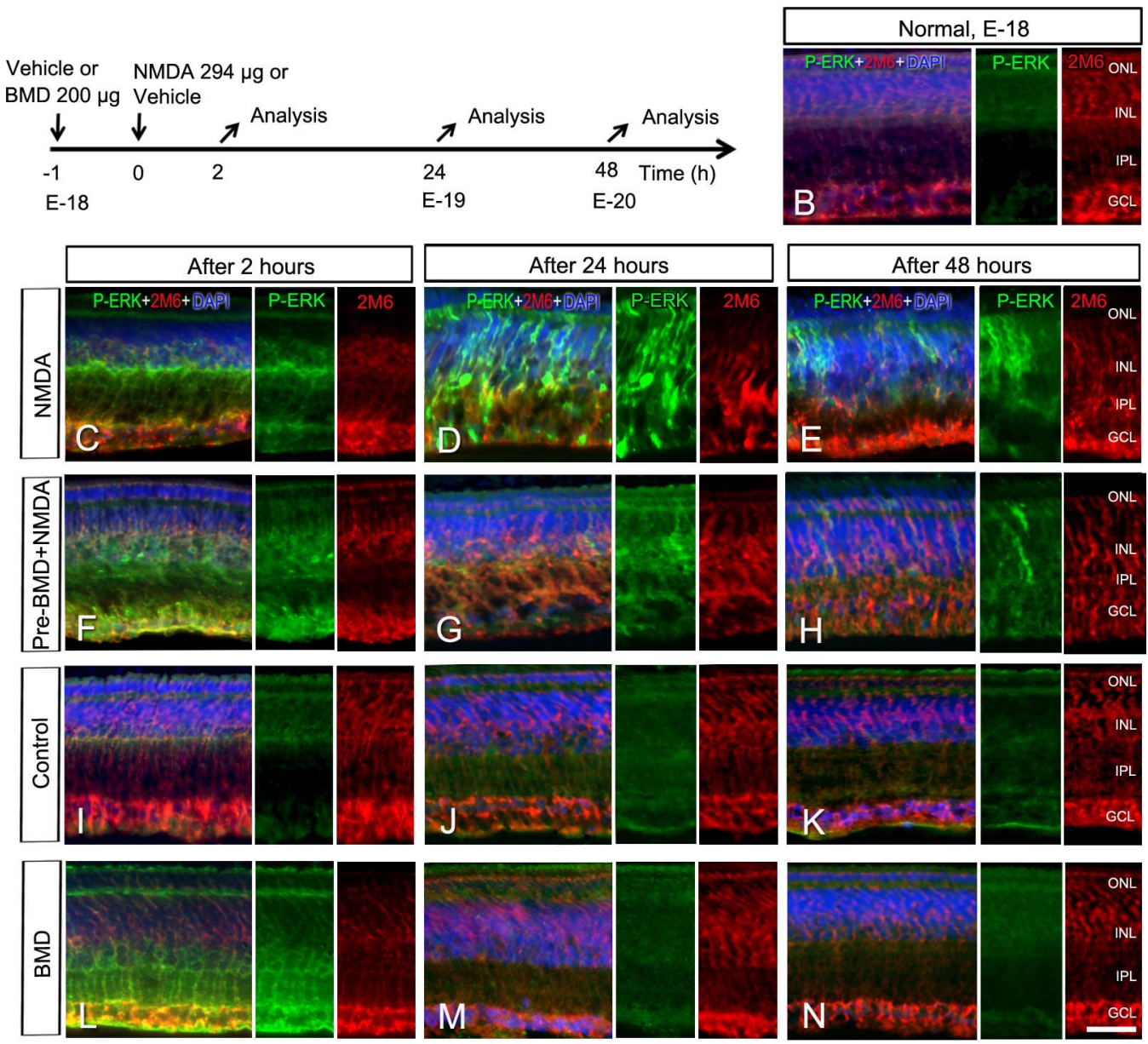

$\mathrm{O}$

$P$
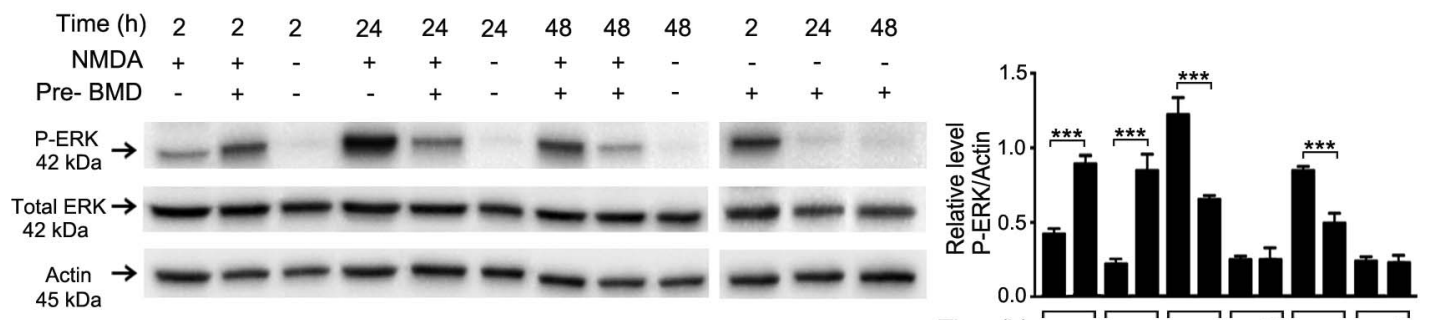

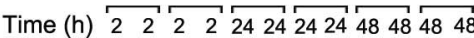

NMDA $++-++\cdots++-\cdot$

Pre-BMD - + - + + + + + - +

FIGURE 1. Brimonidine pretreatment attenuates the phosphorylation of ERK1/2 in NMDA-injured retina. Immunohistochemical analysis of E18 chicken NMDA-injured retina with pretreatment of vehicle (NMDA) or brimonidine (pre-BMD+NMDA), with vehicle injections (control) or untouched retina (normal) or with brimonidine-treated retina (BMD). (A) Experimental outline. (B-N) Representative fluorescence micrographs showing P-ERK and the Müller cell marker 2M6 in (B) untouched normal retina; (C-E) saline-NMDA-injured retina at 2, 24, and 48 hours; (F-H) brimonidine-pretreated NMDA-injured retina at 2, 24, and 48 hours; (I-K) control retina at 2, 24, and 48 hours; (L-N) brimonidine-treated retina at 2, 24, and 48 hours. (O) Western-blot analysis for P-ERK in NMDA-injured, injured BMD-pretreated, vehicle-injected, and brimonidine-treated retinas. (P) Bar graph with densitometry of P-ERK levels normalized to $\beta$-actin levels are mean \pm SEM, $n$ (number of animals) $=3$, **** $P<0.0001,1$ way ANOVA and Tukey's post hoc test. Levels of significance are indicated only for the bracket-grouped treatments. Scale bar: $20 \mu \mathrm{m}$ (N), valid also for (B-M). GCL, ganglion cell layer; IPL, inner plexiform layer; ONL, outer nuclear layer; OPL, outer plexiform layer.

\section{Attenuation of Injury-Induced Expression of Transitin and Progenitor Cell Genes by Brimonidine}

Excitotoxic retinal injury induces activation and dedifferentiation of Müller cells. We studied transitin, the avian homolog of the intermediate filament nestin, to monitor Müller cell activation, ${ }^{19}$ and the number of Pax $6+$ and Sox $2+$ cells in the inner nuclear layer (INL) of the retina to monitor dedifferentiation. ${ }^{20}$ We studied expression after the excitotoxic injury with or without brimonidine pretreatment and after treatment with brimonidine only. Retinas were analyzed after 2, 24, and 48 hours (Fig. 2A). Transitin IR increased in the injured retina compared with control and normal retina (Figs. 2B, 2C, 2I). 
A

Vehicle or NMDA $294 \mu \mathrm{g}$ or

BMD $200 \mu \mathrm{g}$ Vehicle

\begin{tabular}{lllll}
$\downarrow$ & $\downarrow$ & $\pi^{\text {Analysis }}$ & $\nearrow^{\text {Analysis }}$ & \multicolumn{2}{c}{$\nearrow^{\text {Analysis }} \longrightarrow$} \\
-1 & 0 & 2 & 24 & 48 Time $(\mathrm{h})$
\end{tabular}
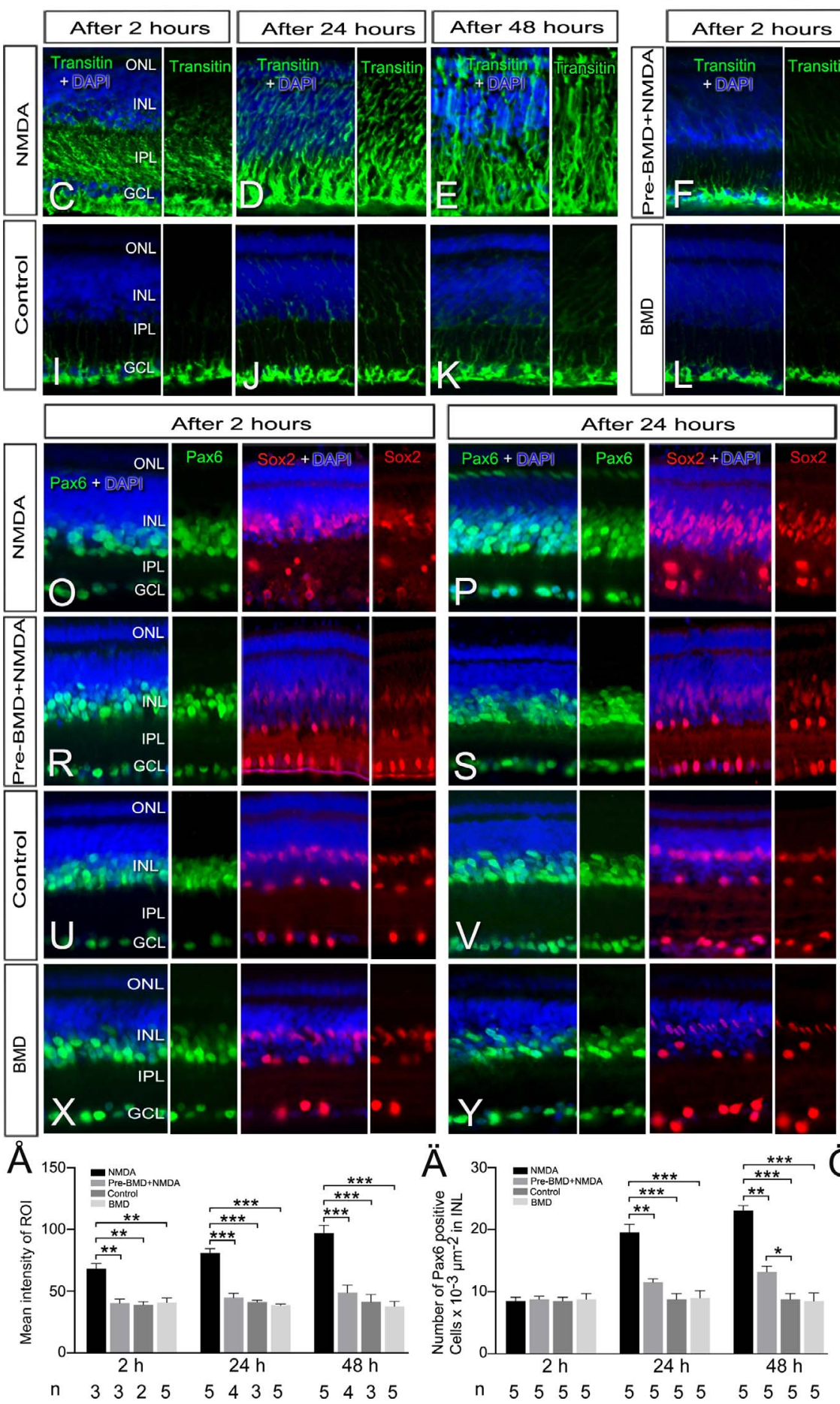
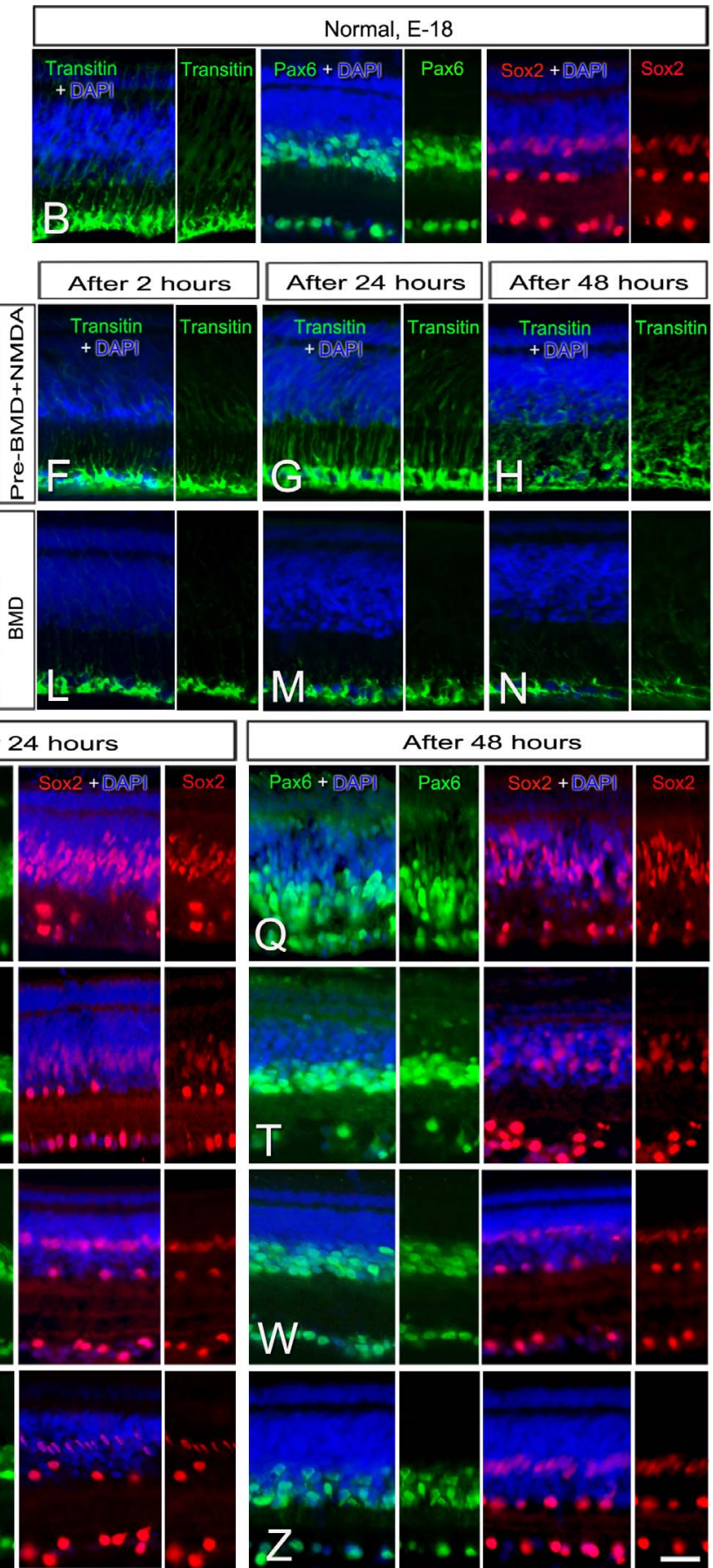

$\sum_{\text {D }}^{Q}$
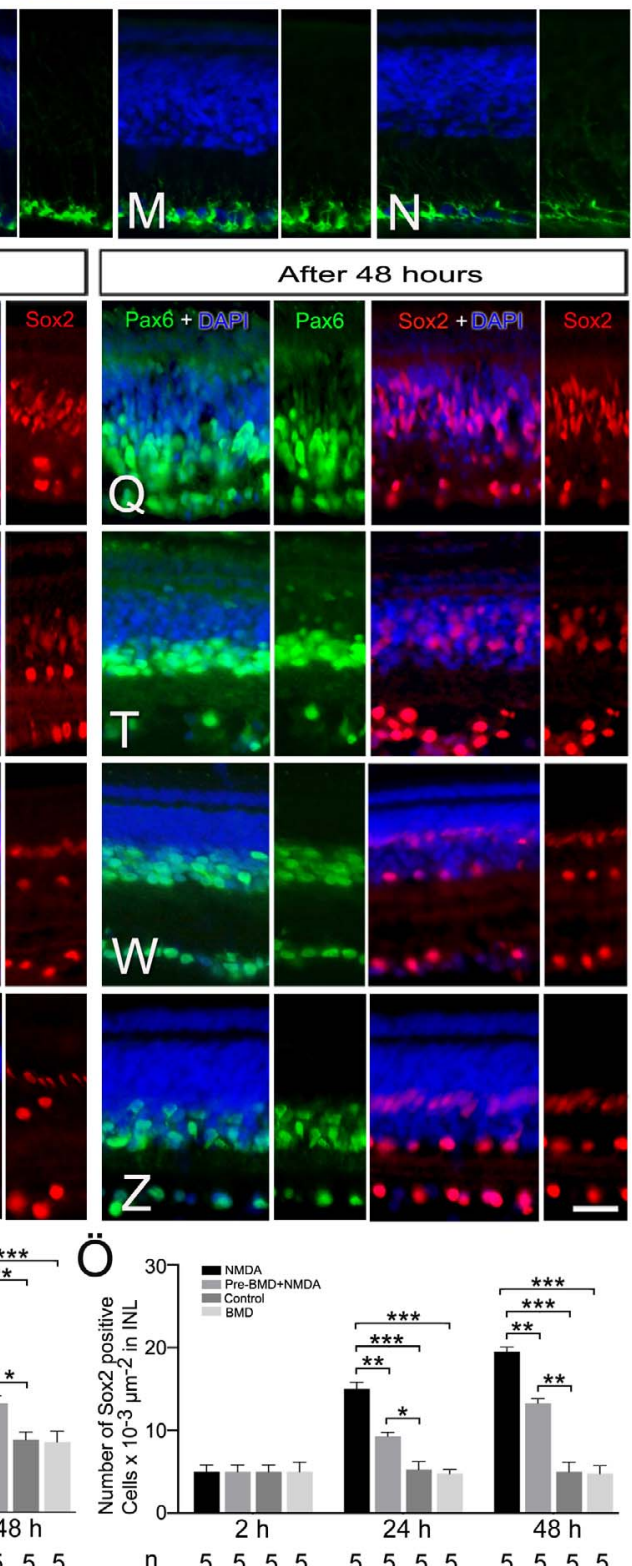

FiguRE 2. Brimonidine pretreatment attenuates injury-induced expression of transitin, Pax6, and Sox2. Immunohistochemical analysis of E18 chicken NMDA-injured retina with pretreatment of vehicle (NMDA) or brimonidine (pre-BMD+NMDA), with vehicle injections (control) or untouched retina (normal). (A) Experimental outline. Representative fluorescence micrographs showing (B-N) transitin and (O-Z) Pax6 and Sox2 in (B) normal retina; (C-E, O-Q) saline-NMDA-injured retina at 2, 24, and 48 hours; (F-H, R-T) brimonidine pretreated NMDA-injured retina at 2, 24, and 48 hours; (I-K, U-W) control retina at 2, 24, and 48 hours; (L-N, X-Z) brimonidine pretreated-saline retina at 2, 24, and 48 hours. Bar graphs show $(\stackrel{\mathbf{A}}{)})$ the mean transitin fluorescence intensity in a fixed region of interest (ROI), and the cell density of $(\ddot{\mathbf{A}})$ Pax 6 and $(\ddot{\mathbf{O}})$ Sox2 positive cells in INL after different treatments. Bar graphs are mean \pm SEM, ${ }^{*} P<0.01{ }^{* *} P<0.001,{ }^{* * * *} P<0.0001,1$-way ANOVA and Tukey's post hoc test. Levels of significance are indicated for the comparisons: control-BMD, control-NMDA, control-Pre BMD+NMDA, NMDA-Pre BMD+NMDA, and BMDPre BMD+NMDA. Scale bar: $20 \mu \mathrm{m}(\mathbf{Z})$, valid also for (B-Y). 
The injury-induced increase was not seen in the group with the brimonidine pretreatment (Fig. 2F). This difference was seen at the 2-, 24-, and 48-hour time-points (Figs. 2D, 2E, 2G, 2H). Brimonidine treatment of noninjured retina did not induce transitin expression (Figs. 2L-N). The fluorescence intensity of transitin IR was quantified and the result showed a significant weaker transitin IR in the brimonidine-pretreated retinas (Fig. $2 \AA)$. The results showed that the injury-induced increase of transitin IR was attenuated by the brimonidine pretreated retina and suggested that the pretreatment reduced the Müller cell activation after the excitotoxic injury.

The number of Pax6+ and Sox $2+$ cells in the INL was counted. Activated Müller cells display increased mobility and the pattern of Sox $2+$ cells in the normal and control groups were similar (Figs. 2B, 2U-W) with a row of Sox $2+$ cells in the central portion of the INL, which are Sox $2+$ Müller cells. ${ }^{15}$ The IR intensity and the number of both Pax6+ and Sox $2+$ cells were similar in the injured retina compared with that of controls at 2 hours, but were higher at the 24- and 48-hour time-points. The increased number of Sox $2+$ cells in the INL was associated with distortion of the normal Sox 2 pattern in the INL (Figs. 2P, 2Q). The increase of Pax6+ and Sox $2+$ cells was attenuated by brimonidine pretreatment, as seen at the 24and 48-hour time-points (Figs. 2O-T). The cell density was compared between the experimental groups and the pretreatment significantly attenuated the increase of Pax6+ and Sox2+ cells after injury (Figs. 2̈̈, 2Ö), suggesting that the Müller cell dedifferentiation was reduced. In total, more than 9375 Pax6+ cells and 7050 Sox $2+$ cells were counted in the 48-hour salineNMDA-treated group, and more than 3000 Pax6+ cells and 2250 Sox $2+$ cells in the 48-hour saline-injected control group. The cell density after brimonidine treatment of noninjured retina was similar to the control and normal retina (Figs. 2B, 2U-Z)

\section{Synergistic Upregulation of DUSPs in Injured Retina Pretreated With Brimonidine}

The results show that pretreatment with brimonidine attenuated the injury-induced activation of ERK. We hypothesized that the attenuation would be a result of increased negative feedback regulation of the ERK pathway. Negative feedback regulation of the ERK/MAPK pathway is effectuated on several levels: by dual-specificity phosphatases (DUSPs), ${ }^{21}$ by proteins that interact with regulatory proteins in the ERK pathway downstream of Ras, by interaction with adaptor proteins or with receptor tyrosine kinases (RTKs). Proteins such as MIG6 and SPRY2 have been shown to negatively regulate Raf, SOS, GRB2, or the EGFR. ${ }^{22-26}$ We identified eight chicken orthologues of relevant phosphatases (DUSP1, 4-8, 10, and PP2A, Supplementary Table S4). Dual-specificity phosphatases are transcriptionally activated, ${ }^{24}$ and we used qRT-PCR to analyze the relative mRNA levels. First we analyzed the expression of all eight phosphatases (Supplementary Fig. S2). Dual-specificity phosphatases 1 and 5 were identified as having increased mRNA levels after injury and after brimonidine treatment. The expression was analyzed 2, 4, 6 , and 12 hours after injury with brimonidine or saline treatment 1 hour prior to injury (Fig. 3A). We compared the expression of DUSP1 and 5 in controls with brimonidine alone or injury with or without brimonidine pretreatment. Brimonidine alone induced a transient increase of DUSP1, as seen at the 2-hour time-point. N-methyl-D-aspartate induced a larger increase than brimonidine, while the combination of NMDA and brimonidine pretreatment gave an even larger increase of both DUSP1 and 5 at 2, 4, and 6 hours (Figs. 3B$\mathrm{D}, \mathrm{F}-\mathrm{H})$. At 12 hours after NMDA, the levels were back at control levels (Figs. 3E, 3I). The pretreatment of injured retina induced a larger increase than the sum of the effects of the treatment and injury alone, indicating a synergistic effect of the brimonidine pretreatment on the increase of the negative feedback. Dual-specificity phosphatases 4 and 10 were included as a comparison and they did not exhibit any effect. The principal action of the DUSPs on ERKsignaling is illustrated in Figure $3 \mathrm{~L}$.

\section{Synergistic Upregulation of ERK Negative Feedback Regulators in Injured Retina Pretreated With Brimonidine}

The expression of the negative ERK and RTK signaling feedback regulators MIG6, SPRED1, 2, and SPRY2 was analyzed at 2, 4, 6, and 12 hours after injury with or without brimonidine pretreatment compared with controls. We observed a synergistic increase of MIG6 and SPRY2 mRNA levels after pretreatment at the 2-hour time-point (Figs. 4B, $4 \mathrm{~F}$ ), and significant increase at 4- and 6-hour time-points (Figs. $4 \mathrm{C}-\mathrm{D}, 4 \mathrm{G}-\mathrm{H})$. The expression of SPRED1 and 2 were not significantly altered after injury or brimonidine treatment at 2 hours (Figs. 4J-K) or at 4, 6, or 12 hours (data not shown). The principal actions of the negative regulators are shown in Figure 4L.

\section{Brimonidine Reduced Progenitor Cell Gene Expression in EGF or FGF2-Stimulated Müller Cells In Vitro}

Epidermal growth factor and FGF2 trigger the ERK1/2 pathway leading to dedifferentiation of Müller cells ${ }^{4,6}$ and long-term stimulation of Müller cells in culture with EGF has been shown to induce progenitor cell features. ${ }^{27}$ Primary Müller cell cultures were long term-stimulated with EGF or FGF2 with or without brimonidine and we analyzed the mRNA expression of progenitor cell genes: Sox2, transitin, Chx10, FOXN4, CASH1, and $p 75 N T R$. The Müller cell cultures were supplemented every third day with growth factors and/or brimonidine during 2 weeks and were then analyzed (Fig. 5A). Consistent with previous data, ${ }^{27}$ long-term stimulation of Müller cells with EGF or FGF2 led to increased expression of transitin and other progenitor cell genes Sox2, Chx10, and p75NTR (Figs. 5B-E). The combined stimulation of brimonidine and EGF or FGF, significantly decreased the mRNA levels of Sox2, Transitin, and Chx10 compared with stimulation with EGF alone. The combined treatment of brimonidine and FGF2 also significantly decreased the mRNA levels of Sox2, Transitin, Chx10, and p75NTR compared with FGF2 alone (Figs. 5B-E). The expression of FOXN4 and CASH1 was low in the cultured Müller cell from the beginning and remained low after the treatment with brimonidine and/or EGF or FGF2 (Figs. 5F, 5G).

\section{Upregulation of Negative Feedback Regulators in Müller Cells After Brimonidine Pretreatment In Vitro}

We studied the negative ERK pathway regulators after pretreatment with brimonidine and EGF or FGF2-stimulation in vitro. Brimonidine was added to serum-starved cultures of primary Müller cells 1 hour prior to addition of EGF or FGF2. Messenger RNA expression of DUSP 1, 5, 4, and 10 as well as MIG6, SPRY2, and SPRED1 and 2 was analyzed by qRT-PCR after 1 and 2 hours (Figs. 6A). The result showed that pretreatment with brimonidine significantly increased mRNA levels of DUSP1, DUSP5, and MIG6 compared with EGF or FGF2 alone (Figs. 6B-C, 6F). The expression of DUSP10, 
A

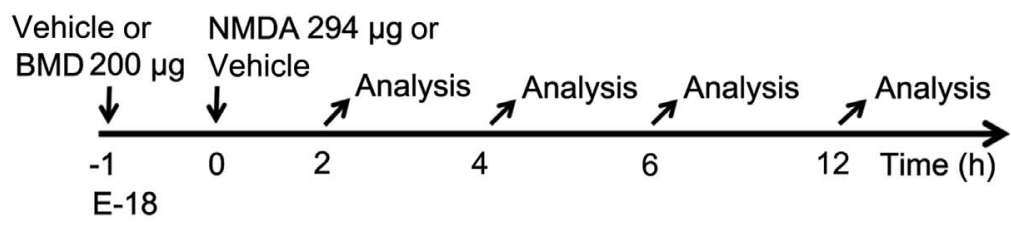

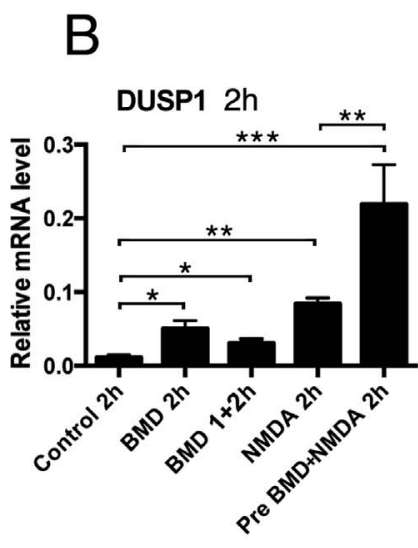

C

D

DUSP1 $6 \mathrm{~h}$

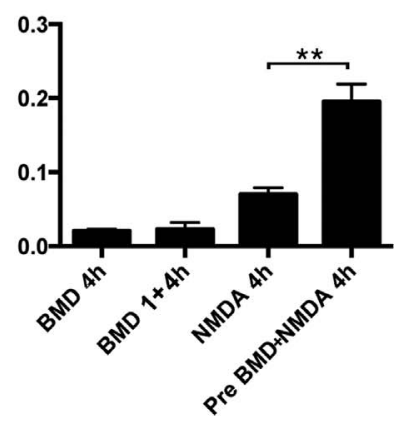

G

DUSP5 $2 \mathrm{~h}$

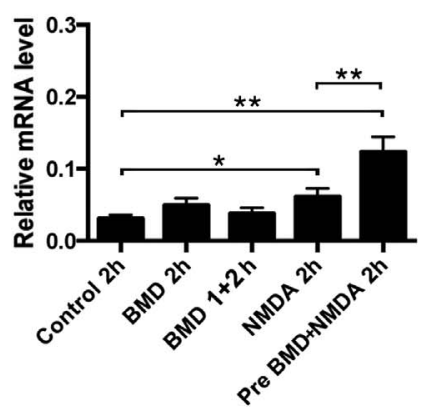

J

DUSP4 $2 h$

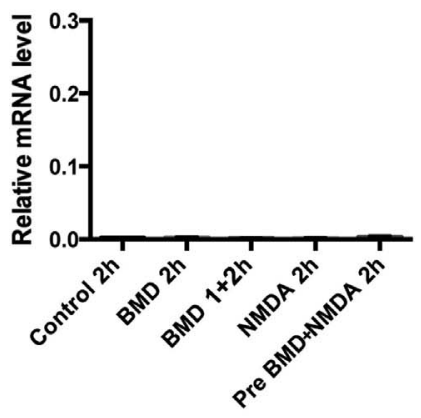

DUSP5 $4 \mathrm{~h}$

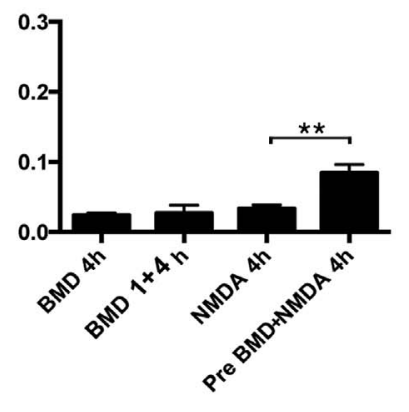

K
DUSP5 $6 \mathrm{~h}$

$\mathrm{L}$

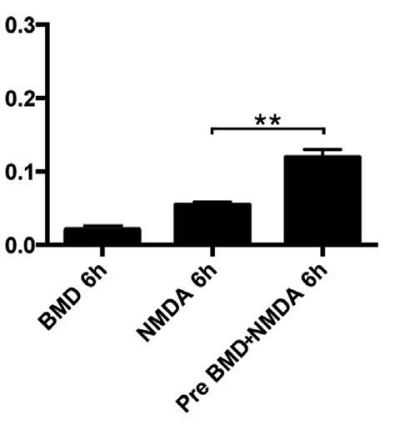

$\mathrm{H}$
E

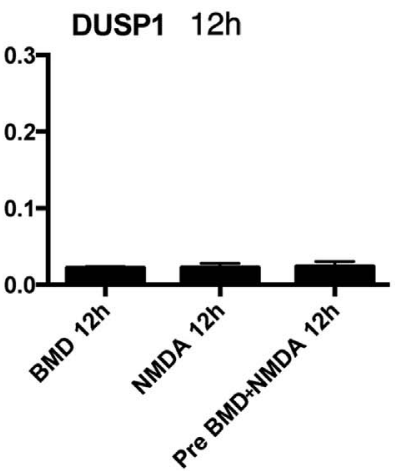

I

DUSP5 $12 \mathrm{~h}$
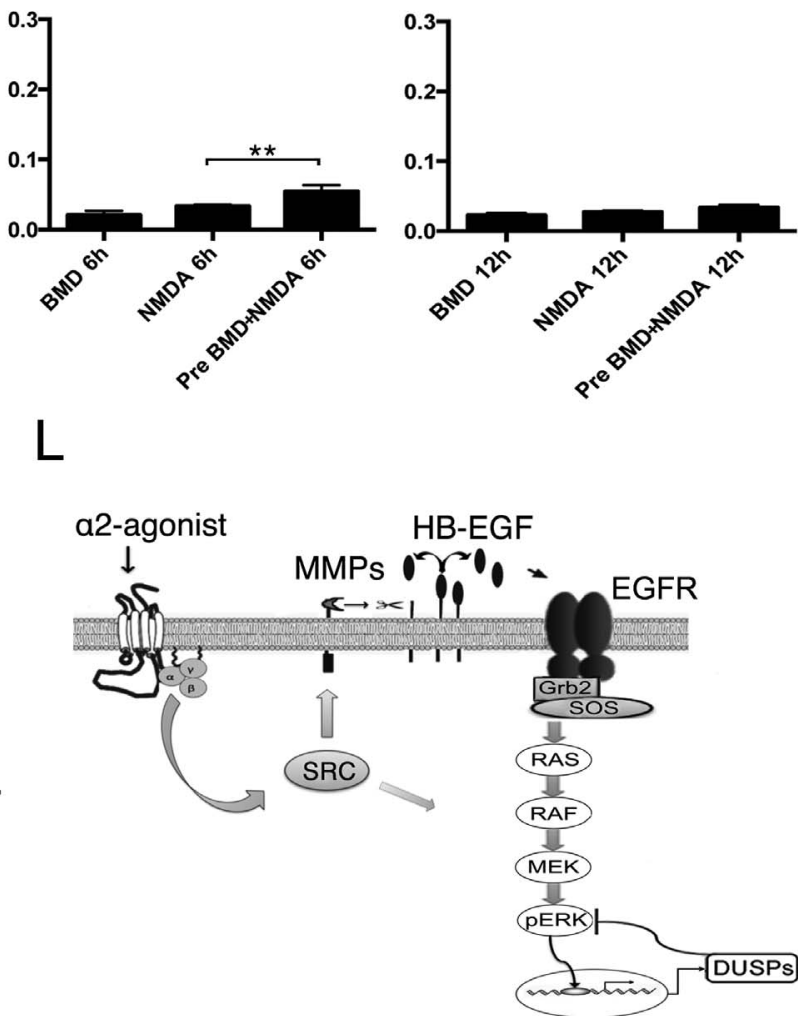

FIGURE 3. Brimonidine pretreatment increases the expression of dual specificity phosphatases in retina. Quantitative RT-PCR analysis of dual specificity phosphatases (DUSP) mRNA levels in brimonidine-treated (BMD), NMDA-injured E18 chicken retina with pretreatment of vehicle (NMDA), or brimonidine (pre BMD+NMDA), or vehicle-injected eyes (control). Bar graphs show the relative mRNA levels for (B-E) DUSP1 at 2, 4 , 6, and 12 hours, for (F-I) DUSP5 at 2, 4, 6, and 12 hours, for (J) DUSP4 at 2 hours, and for (K) DUSP10 at 2 hours. (L) Schematic diagram showing $\alpha 2$-adrenergic receptor-induced ERK signaling and the actions of negative feedback DUSP regulator. Bar graphs are mean \pm SEM, $n=5,{ }^{*} P<0.01$, ${ }^{* *} P<0.001,{ }^{* * *} P<0.0001,1$-way ANOVA and Tukey's post hoc test. Levels of significance are indicated for the comparisons: control-BMD, controlNMDA, control-Pre BMD+NMDA, and NMDA-Pre BMD+NMDA. 
A

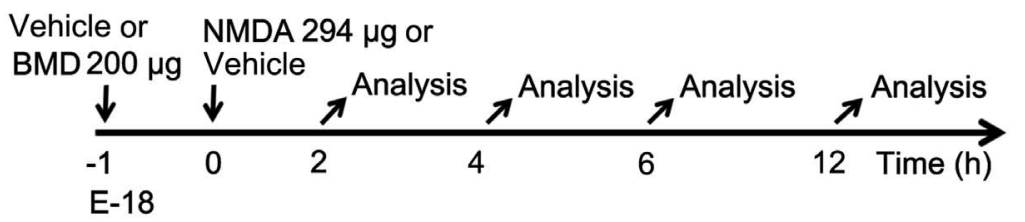

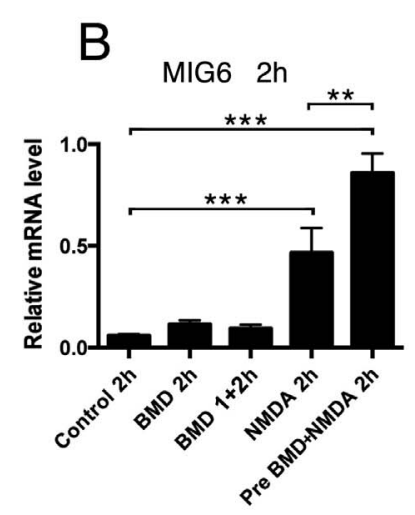

F

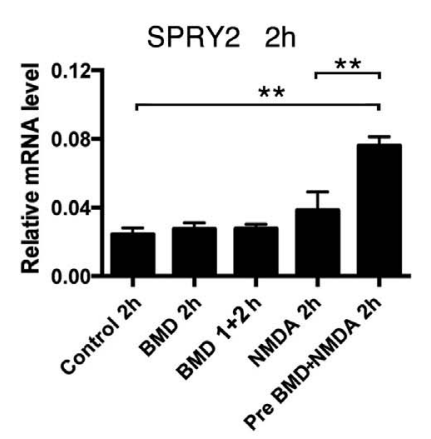

J

SPRED1 2h

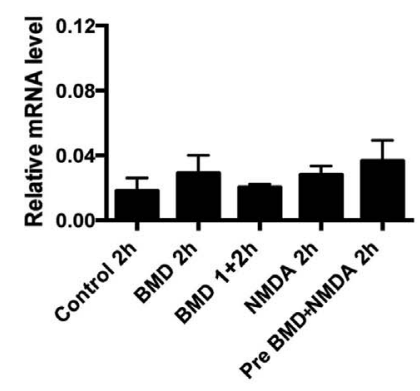

C

MIG6 4h

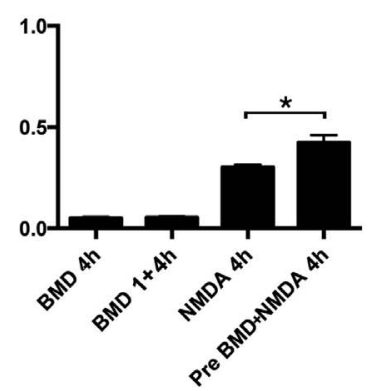

G

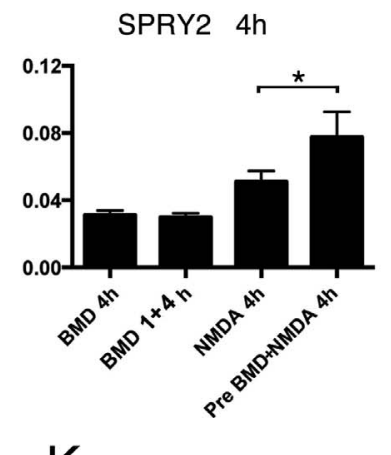

K

SPRED2 $2 \mathrm{~h}$

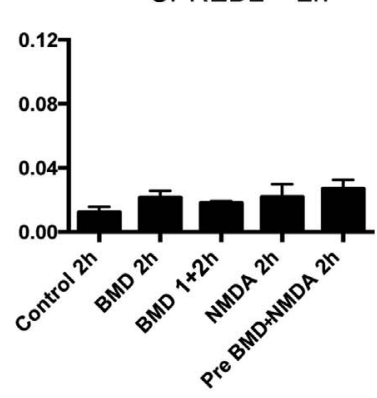

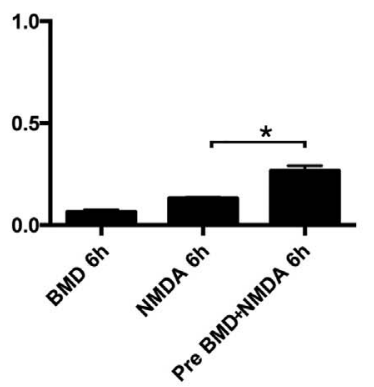

$\mathrm{H}$

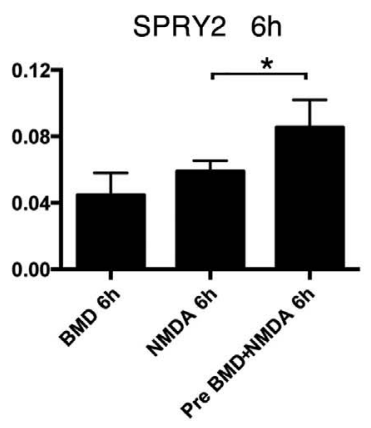

L
E MIG6 $12 \mathrm{~h}$

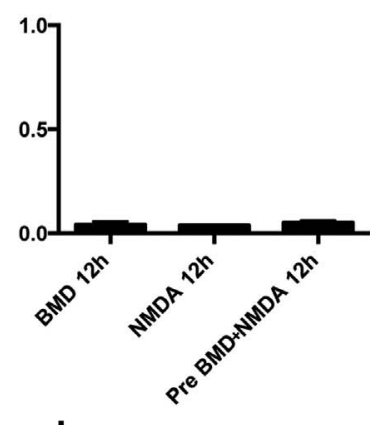

I
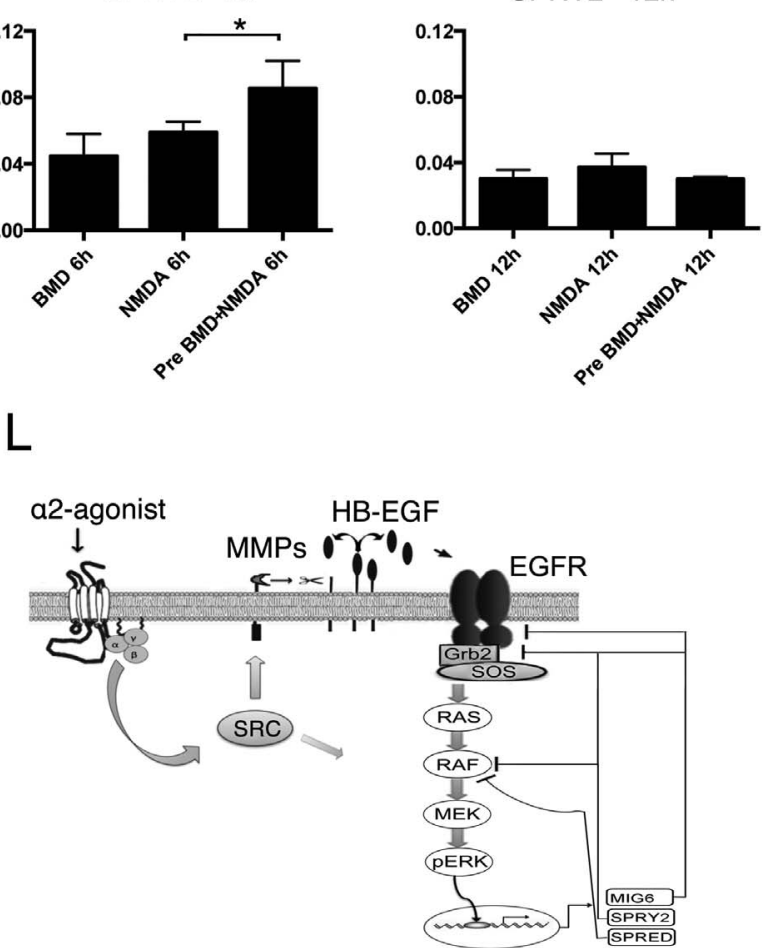

FIGURE 4. Brimonidine pretreatment increases the expression of negative regulators of ERK/MAPK pathway in the retina. Quantitative RT-PCR analysis of MIG6, SPRY2, SPRED1, and SPRED2 mRNA levels in brimonidine-treated (BMD) or NMDA-injured E18 chicken retina with pretreatment of vehicle (NMDA) or brimonidine (pre-BMD+NMDA), or vehicle-injected eyes (control). (A) Experimental outline. Bar graphs show the relative mRNA levels of (B-E) MIG6 at 2, 4, 6, and 12 hours, (F-I) SPRY2 at 2, 4, 6, and 12 hours, (J) SPRED1 at 2 hours, and (K) SPRED2 at 2 hours. (L) Schematic diagram showing $\alpha 2$-adrenergic receptor-induced ERK signaling and the actions of negative feedback regulators. Bar graphs are mean \pm SEM, $n=5,{ }^{*} P<0.01,{ }^{* *} P<0.001,{ }^{* * *} P<0.0001,1$-way ANOVA and Tukey's post hoc test. Levels of significance are indicated for the comparisons: control-BMD, control-NMDA, control-Pre BMD+NMDA, and NMDA-Pre BMD+NMDA.

SPRY2, and SPRED1 was increased after brimonidine treatment but not in the other treatment groups (Figs. 6E, 6G, 6H). DUSP 4 or SPRED2 expression did not change after the different treatments (Figs. 6D, 61).

\section{a2-ADR-Antagonist Blocked the Upregulation of Negative Regulators in Müller Cells}

To certify that the upregulation of the negative ERK regulators by brimonidine was mediated by $\alpha 2$-ADR signaling, we added 


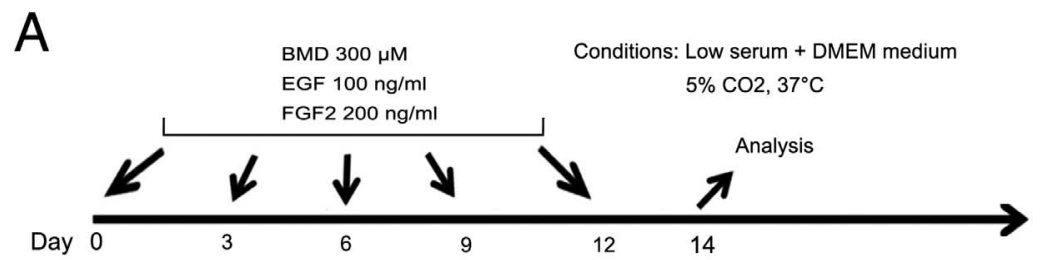

B

Sox2

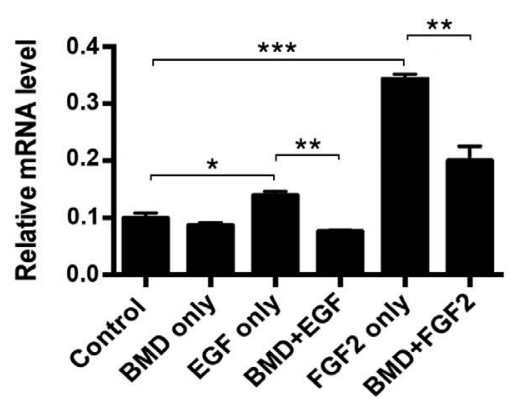

Transitin

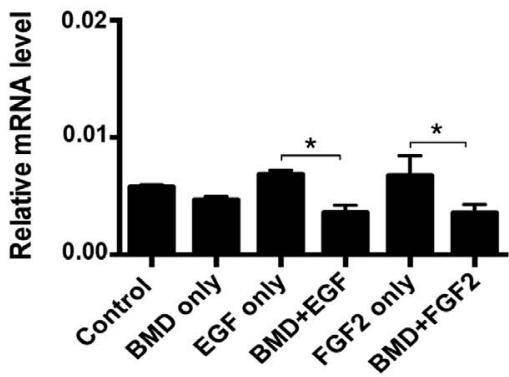

F

FOXN4

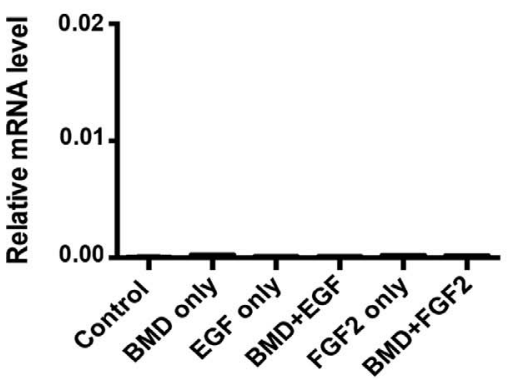

C

\section{p75NTR}

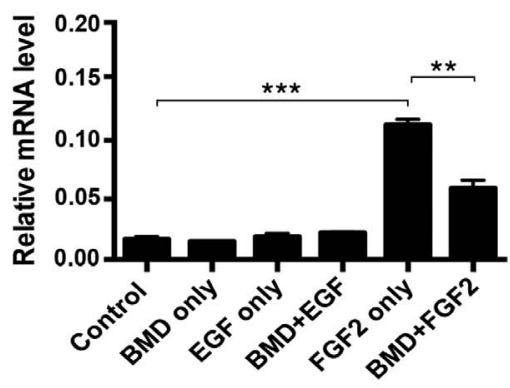

E

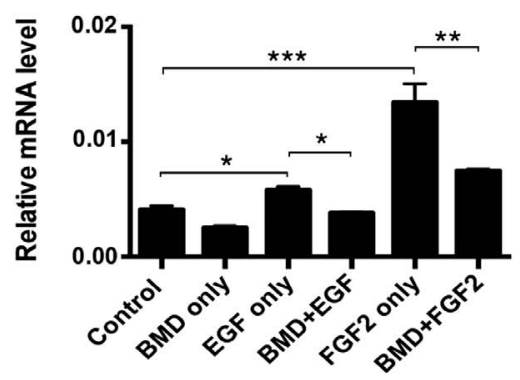

G

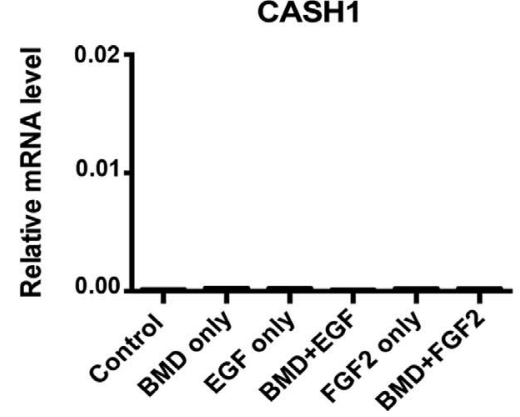

FigURE 5. Expression of progenitor genes after cotreatment of primary Müller cells with EGF or FGF2 and brimonidine. Quantitative RT-PCR analysis of primary Müller cells cotreated with EGF or FGF2 and brimonidine (BMD) for 2 weeks. (A) Experimental outline. Bar graphs show the relative mRNA levels of (B) Sox2, (C) p75NTR, (D) Transitin, (E) Chx10, (F) FOXN4, and (G) CASH1 mRNA levels. Bar graphs are mean \pm SEM, $n=$ $5,{ }^{*} P<0.01,{ }^{* *} P<0.001,{ }^{* * * *} P<0.0001,1-$ way ANOVA and Tukey's post hoc test. Levels of significance are indicated for the comparisons: controlBMD, control-EGF only, control-BMD+EGF, control-FGF2 only, control-BMD+FGF2, EGF only-BMD+EGF, and FGF2 only-BMD+FGF2.

the $\alpha 2$-ADR blocker, yohimbine to the cultures (Fig. 7A). ${ }^{28}$ The yohimbine treatment of primary Müller cells has previously been established. ${ }^{3}$ Quantitative RT-PCR analysis showed that pretreatment with yohimbine reduced the mRNA levels of DUSP1, 5, and 10, MIG6, SPRY2, and SPRED1 significantly (Figs. 7B-E). Müller cell cultures that were supplemented with only yohimbine did not alter the expression. This result indicated that the increase of negative ERK feedback seen by brimonidine, was mediated by $\alpha 2$-ADRs.

\section{Discussion}

Our results showed that the NMDA injury increases P-ERK in retina and specifically in the Müller cells. Transitin expression 


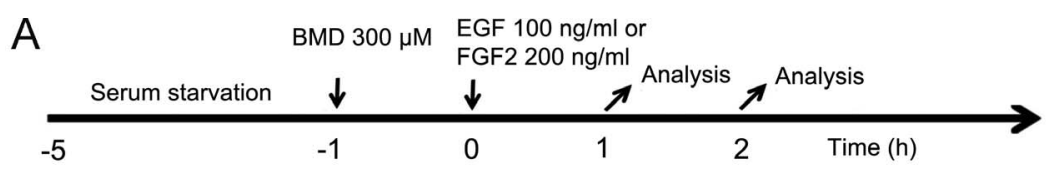

B

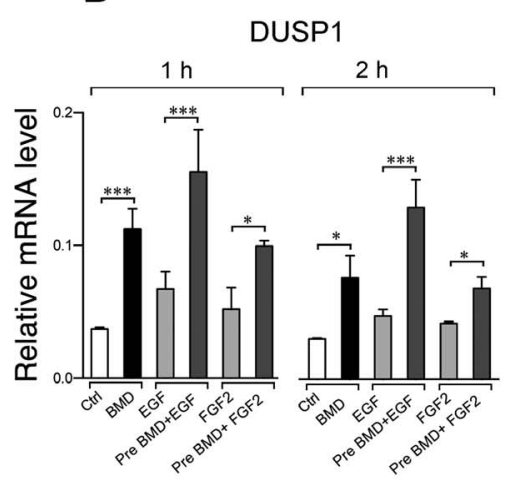

F

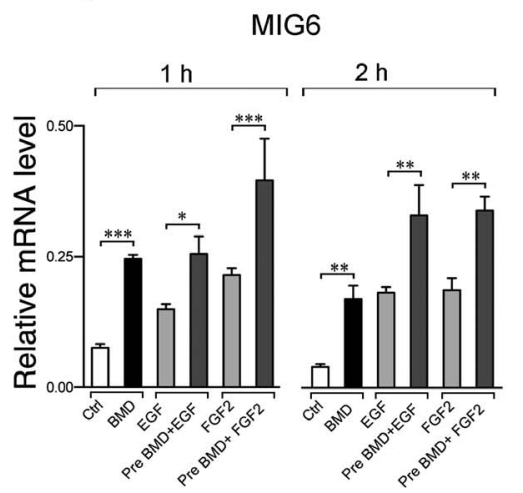

C

G

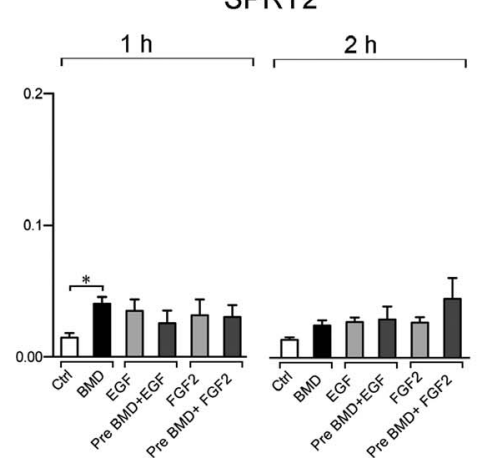

D

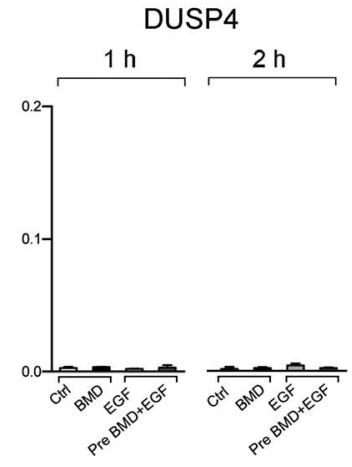

$\mathrm{H}$
E

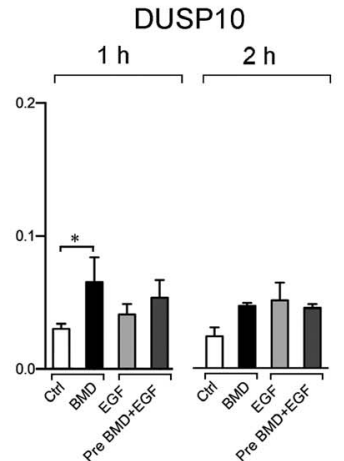

I

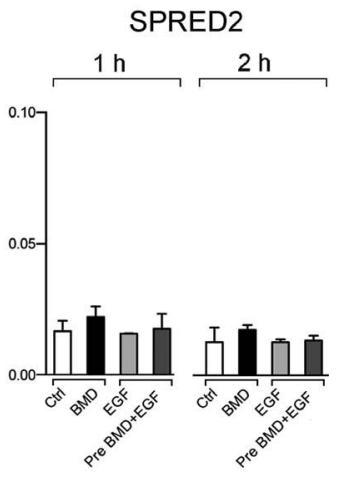

FigURE 6. Brimonidine-treatment of primary Müller cells prior to EGF or FGF2-treatment increases the expression of DUSPs and negative regulators of ERK signaling. Quantitative RT-PCR analysis of serum-starved primary Müller cells treated with brimonidine (BMD) or vehicle followed by EGF, FGF2, or vehicle. (A) Experimental outline. Bar graphs show the relative mRNA levels of (B) DUSP1, (C) DUSP5, (D) DUSP4, (E) DUSP10, (F) MIG6, (G) SPRY2, (H) SPRED1, and (I) SPRED2. Bar graphs are mean \pm SEM, $n=5,{ }^{*} P<0.01,{ }^{* *} P<0.001,{ }^{* * *} P<0.0001$, 1-way ANOVA and Tukey's post hoc test. Levels of significance are indicated only for the grouped treatments.

also increased in Müller cells and so did the number of Pax6+ and Sox $2+$ cells. Pretreatment with an injection of the $\alpha 2$-ADR agonist brimonidine 1 hour prior to the NMDA injury attenuated the increase of P-ERK as well as the increase of transitin expression and the increase of Pax6+ and Sox $2+$ cells. The pretreatment triggered a robust intracellular response with several negative feedback regulators of the ERK/MAPK pathway. A similar result was achieved in culture when primary Müller cells were supplemented with brimonidine and growth factors. The results indicate that $\alpha 2$-ADRs on Müller cells elicit an intracellular signal that modulates the response to injury, which leads to attenuation of Müller cell dedifferentiation.

Treatment in glaucoma aims to lower IOP to reduce the risk of disease progression and vision loss. Brimonidine lowers IOP and is used as therapy in open-angle glaucoma and ocular hypertension. The preclinical studies suggest that brimonidine may protect retinal ganglion cells and their projections from damage independently of its effects on the IOP. This potential for neuroprotection is an added benefit of its use in glaucoma and our data suggest an additional and potential mechanism for how these effects may be exerted. However, it remains to be studied if human cells respond in a similar way as the chicken cells do and if the mechanism of impact, which is proposed in this work during an acute injury is also valid during disease. The results provide support to the idea that Müller cell function or malfunction is a factor that may affect progression of glaucoma.

Our results are consistent with data showing that the progress of the injury is ERK-dependent ${ }^{5}$ and that increased expression of phosphatases negatively regulates the ERK/ MAPK pathway. ${ }^{21,24,29}$ Our results are also consistent with data showing that signaling emanating from $G$ protein-coupled receptors, such as ADRs, have an extensive crosstalk with other pathways including the ERK pathway, often resulting in negative modulation of the signals. ${ }^{22}$ The concept that the extent and duration of intracellular ERK/MAPK signaling may regulate cell differentiation is well known. Transient versus sustained ERK-activation is directly regulating the choice of proliferation or differentiation in pheochromocytoma 12 cells after stimulation with EGF or nerve growth factor. ${ }^{30}$ Sympathetic neurons that correspond to the differentiated form of pheochromocytoma cells respond with MAP kinase phosphatase-1 (DUSP1) expression after nerve growth factor stimulation. ${ }^{31}$ The attenuation of the injury-increased number of Pax6+ and Sox $2+$ cells is indicative of altered differentiation. Sox 2 and Pax 6 are expressed in Müller cell progenitors ${ }^{32}$ and their expression decreases as development proceeds. ${ }^{33}$ Pax6 expression in Müller glia increase after NMDA injury in postnatal chick retina ${ }^{19}$ and sustained Sox2 expression is required to maintain the progenitor state of Müller cells in 

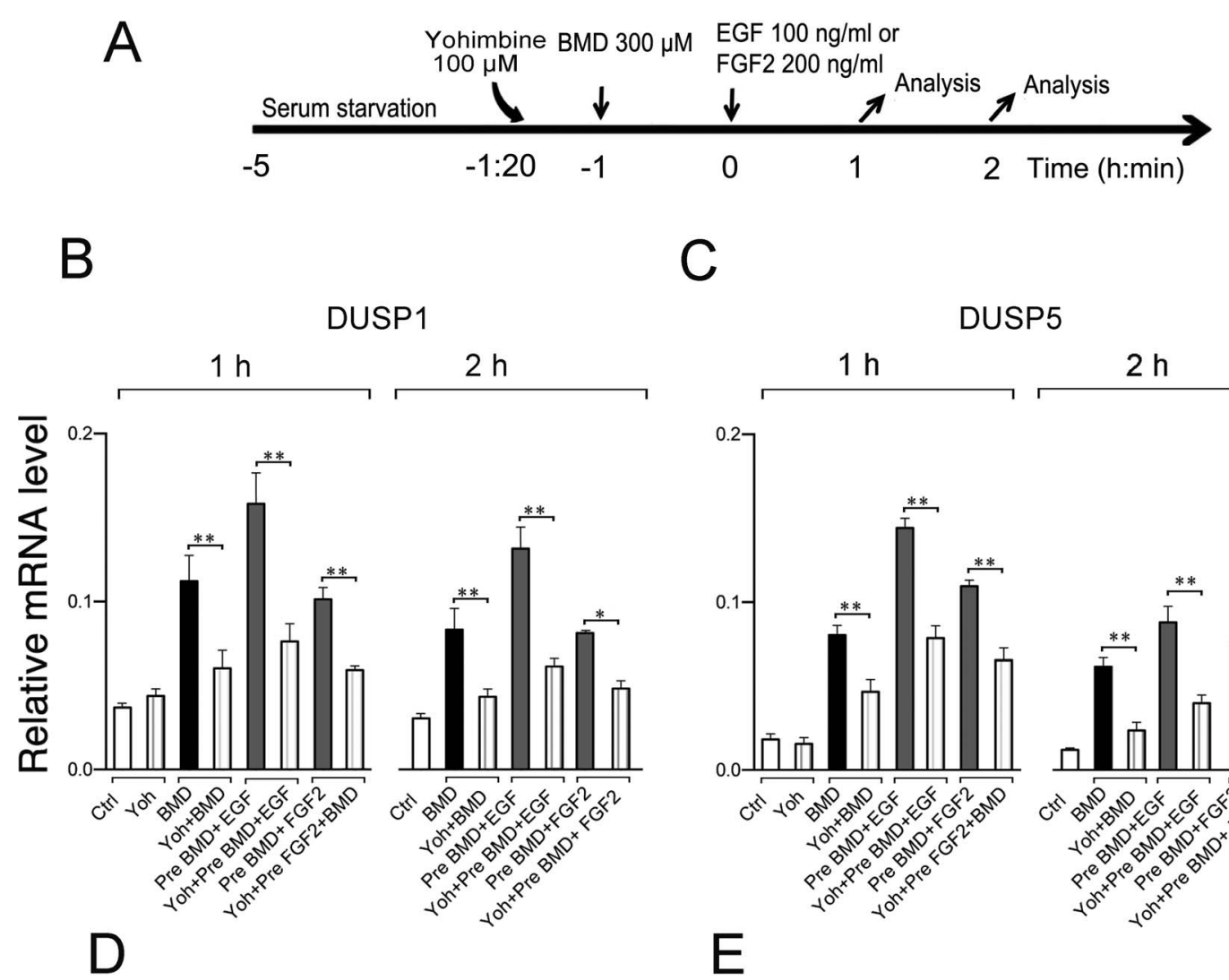

MIG6
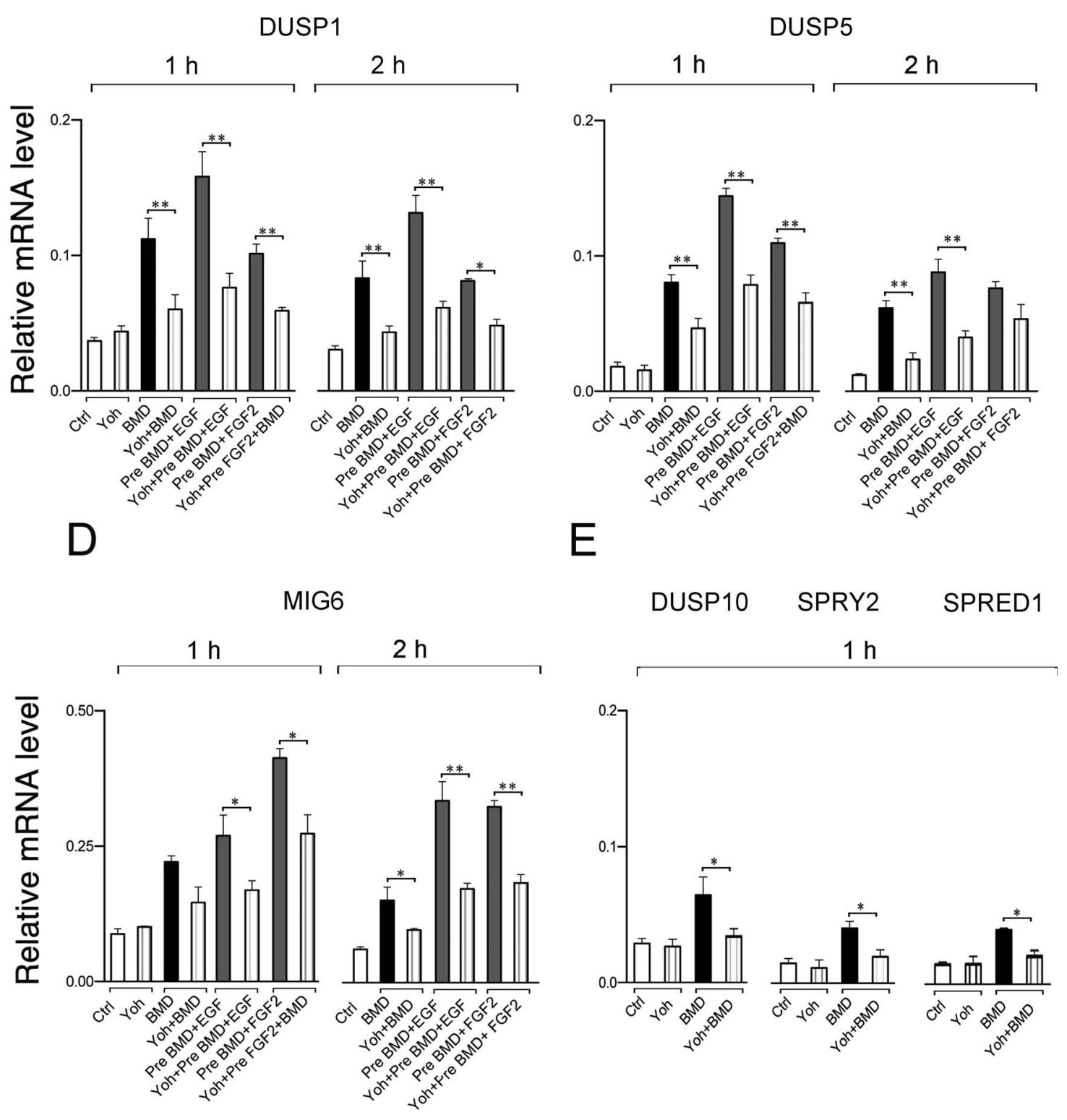

FIGURE 7. Inhibition of brimonidine-induced upregulation of DUSPs and negative regulators of ERK signaling in primary Müller cells by yohimbine. Quantitative RT-PCR analysis of serum-starved primary Müller cells treated prereated with the $\alpha 2$-adrenergic receptor antagonist, yohimbine (Yoh) or vehicle (ctrl), brimonidine (BMD), or vehicle followed by EGF, FGF2, or vehicle. (A) Experimental outline. Bar graphs show the relative mRNA levels of (B) DUSP1, (C) DUSP5, (D) MIG6, (E) DUSP10, (E) SPRY2, and (E) SPRED1. Bar graphs are mean \pm SEM, $n=5,{ }^{*} P<0.01$, ${ }^{* *} P<0.001,1-$ way ANOVA and Tukey's post hoc test. Levels of significance are indicated only for the grouped treatments.

postnatal mouse retina. ${ }^{34,35}$ Thus, the brimonidine-induced attenuation of these progenitor cell markers supports the hypothesis that $\alpha 2 \mathrm{~A}-\mathrm{ADRs}$ inhibit dedifferentiation of Müller cells in the injured retina.

Modulation of ADR activity has been shown to affect nestin/ GFAP-positive progenitor cells in the adult hippocampus where selective stimulation of $\alpha 2$-ADR inhibits ${ }^{36}$ and selective inhibition of $\alpha 2$-ADR activates the progenitor cell. ${ }^{37}$ Acute stimulation of $\alpha 2$-ADR also inhibits hematopoietic stem cells via the ERK/MAPK pathway. ${ }^{38}$ Several $\alpha 2$-ADR agonists exhibit neuroprotective effects in addition to their anesthetic effects. Early results showed that dexmedetomidine protects against cerebral ischemia, ${ }^{39}$ xylazine and clonidine attenuate photoreceptor loss after phototoxicity, ${ }^{7,40}$ and brimonidine attenuates retinal ganglion cell loss after optic nerve degeneration. ${ }^{8,9}$ The protective effect of xylazine has specifically been addressed 
because it is often used as anesthetics for animals and the effect was confirmed in a study comparing the effects of different anesthetics on retinal ganglion cell survival after retinal injury. $^{41}$ Brimonidine was developed as a glaucoma drug ${ }^{42}$ because it lowers the IOP, ${ }^{43,44}$ and therefore the neuroprotective effects by brimonidine has attracted interest. It attenuates cell loss induced by vascular ischemia,,${ }^{9,45,46}$ by high IOP, ${ }^{10,47,48}$ and by optic nerve crush or ischemia. ${ }^{49,50}$ Brimonidine also preserves retrograde axonal transport ${ }^{51}$ and limits degeneration of the retinotectal projection after retinal ischemia. ${ }^{52,53}$ Common for these studies is that the effective treatment is prior to injury ( 1 hour) and is considerably lower when performed 1 hour or later after the injury. ${ }^{9}$ This is intriguing when compared with the transient nature of the negative feedback regulation in retina seen in this study. Even though the expression of negative regulators has a transient duration of 4 to 6 hours, the attenuation of P-ERK levels remained for 48 hours or more. One interpretation is that in order to achieve effective long-term protection by brimonidine the level of negative ERK feedback regulators needs to be elevated in the Müller cells at the time of injury. Phospho-ERK1/2 levels were higher with the NMDA injection compared with control at 2 hours and at that time the negative regulators were already increased (Figs. 3B, 3F). We speculate that in order to promote neuroprotection, the $\alpha 2$-ADR stimulation must "revise" the profile or duration of injury-induced intracellular signals including P-ERK. That may be achieved by the activation of negative feedback regulators. Brimonidine-treatment of normal noninjured retina triggers a robust ERK-activation. ${ }^{3}$ We did however not see any change of transitin expression or number of Sox $2+$ or Pax6+ cells after 24 or 48 hours, suggesting that brimonidine alone will not cause any acute major changes but rather seem to revise an injury-response.

We used NMDA to produce an injury that activates Müller cell dedifferentiation and produce retinal damage with cell loss. Our results show that pretreatment with brimonidine of embryonic day 18 chicken retina 1 hour before injury attenuated the NMDA-induced Müller cell activation. In a separate series of experiments, we have confirmed that brimonidine protected the chicken retina against NMDAexcitotoxic injury and brimonidine reduced cell loss in a similar fashion as seen in other injury models (Galindo-Romero C, Harun-Or-Rashid M, Hallböök F, manuscript in preparation, 2015). Taken together, the data imply an association between the protective effects of brimonidine and the attenuated Müller cell response. This is consistent with the idea that Müller cells are involved in the protection. However, the signaling after injury, which activates Müller cells is complex (reviewed for the teleost fish $^{54}$ ) and activated microglia are likely to be involved in the injury response. Microglia inhibitory factor attenuates retinal ganglion cell loss after optic nerve injury in rat $^{55}$ and ablation of microglia in NMDA injured chicken retina affected the formation and proliferation of dedifferentiated Müller cells. ${ }^{56}$ Our results based on the pure Müller cell cultures show that Müller cells respond directly and is the target of the adrenergic signaling with immediate early ERK/ MAPK signaling and a robust response of negative regulation of both ERK and RTK signaling.

In conclusion, the implications of this study are that adrenergic stress signals may directly modulate acute glial function in retina and $\alpha 2$-ADR pharmacology may even be used to control glial injury response.

\section{Acknowledgments}

The authors thank Manuel Vidal-Sanz for valuable comments.

Supported by grants from the Swedish Research Council M 12187 (Stockholm, Sweden), Ögonfonden, Stiftelsen Kronprinsessan
Margaretas Arbetsnämnd för synskadade, FPU-UM (R-480/2014, Universidad de Murcia, Espinardo, Murcia, Spain) and Red Temática de Investigación Cooperativa en Salud (RETICS RD12/ 0034/0014, Spanish Ministry of Economy and Competitiveness, Madrid, Spain.

Disclosure: M. Harun-Or-Rashid, None; M. Díaz-DelCastillo, None; C. Galindo-Romero, None; F. Hallböök, None

\section{References}

1. Peng M, Li Y, Luo Z, Liu C, Laties AM, Wen R. Alpha2adrenergic agonists selectively activate extracellular signalregulated kinases in Müller cells in vivo. Invest Ophthalmol Vis Sci. 1998;39:1721-1726.

2. Woldemussie E, Wijono M, Pow D. Localization of alpha 2 receptors in ocular tissues. Vis Neurosci. 2007;24:745-756.

3. Harun-Or-Rashid M, Lindqvist N, Hallbook F. Transactivation of EGF receptors in chicken Muller cells by alpha2A-adrenergic receptors stimulated by brimonidine. Invest Ophthalmol Vis Sci. 2014;55:3385-3394.

4. Wan J, Ramachandran R, Goldman D. HB-EGF is necessary and sufficient for Müller glia dedifferentiation and retina regeneration. Dev Cell. 2012;22:334-347.

5. Fischer AJ, Scott MA, Ritchey ER, Sherwood P. Mitogenactivated protein kinase-signaling regulates the ability of Muller glia to proliferate and protect retinal neurons against excitotoxicity. Glia. 2009;57:1538-1552.

6. Fischer AJ, Scott MA, Tuten W. Mitogen-activated protein kinase-signaling stimulates Muller glia to proliferate in acutely damaged chicken retina. Glia. 2009;57:166-181.

7. Wen R, Cheng T, Li Y, Cao W, Steinberg RH. Alpha 2-adrenergic agonists induce basic fibroblast growth factor expression in photoreceptors in vivo and ameliorate light damage. $J$ Neurosci. 1996;16:5986-5992.

8. Yoles E, Wheeler LA, Schwartz M. Alpha2-adrenoreceptor agonists are neuroprotective in a rat model of optic nerve degeneration. Invest Ophthalmol Vis Sci. 1999;40:65-73.

9. Lafuente MP, Villegas-Perez MP, Sobrado-Calvo P, Garcia-Aviles A, Miralles de Imperial J, Vidal-Sanz M. Neuroprotective effects of alpha(2)-selective adrenergic agonists against ischemiainduced retinal ganglion cell death. Invest Ophthalmol Vis Sci. 2001;42:2074-2084.

10. WoldeMussie E, Ruiz G, Wijono M, Wheeler LA. Neuroprotection of retinal ganglion cells by brimonidine in rats with laserinduced chronic ocular hypertension. Invest Ophthalmol Vis Sci. 2001;42:2849-2855.

11. Seki M, Tanaka T, Sakai Y, et al. Müller cells as a source of brainderived neurotrophic factor in the retina: noradrenaline upregulates brain-derived neurotrophic factor levels in cultured rat Müller cells. Neurochem Res. 2005;30:1163-1170.

12. Lonngren $\mathrm{U}$, Napankangas $\mathrm{U}$, Lafuente $\mathrm{M}$, et al. The growth factor response in ischemic rat retina and superior colliculus after brimonidine pre-treatment. Brain Res Bull. 2006;71:208218.

13. Dong CJ, Guo Y, Agey P, Wheeler L, Hare WA. Alpha2 adrenergic modulation of NMDA receptor function as a major mechanism of RGC protection in experimental glaucoma and retinal excitotoxicity. Invest Ophthalmol Vis Sci. 2008;49: 4515-4522.

14. Boije H, Harun-Or-Rashid M, Lee YJ, et al. Sonic hedgehogsignalling patterns the developing chicken comb as revealed by exploration of the pea-comb mutation. PLoS One. 2012;7: e50890. 
15. Boije H, Ring H, Lopez-Gallardo M, Prada C, Hallbook F. Pax2 is expressed in a subpopulation of Muller cells in the central chick retina. Dev Dyn. 2010;239:1858-1866.

16. Livak KJ, Schmittgen TD. Analysis of relative gene expression data using real-time quantitative PCR and the 2(-Delta Delta C(T)) method. Methods. 2001;25:402-408.

17. Ka S, Markljung E, Ring $\mathrm{H}$, et al. Expression of carnitine palmitoyl-CoA transferase-1B is influenced by a cis-acting eQTL in two chicken lines selected for high and low body weight. Physiol Genomics. 2013;45:367-376.

18. Schlosshauer B, Grauer D, Dutting D, Vanselow J. Expression of a novel Muller glia specific antigen during development and after optic nerve lesion. Development. 1991;111:789-799.

19. Fischer AJ, Omar G. Transitin, a nestin-related intermediate filament, is expressed by neural progenitors and can be induced in Muller glia in the chicken retina. J Comp Neurol. 2005;484:1-14.

20. Fischer AJ. Neural regeneration in the chick retina. Prog Retin Eye Res. 2005;24:161-182.

21. Jeffrey KL, Camps M, Rommel C, Mackay CR. Targeting dualspecificity phosphatases: manipulating MAP kinase signalling and immune responses. Nat Rev Drug Discov. 2007;6:391403.

22. Liebmann C, Bohmer FD. Signal transduction pathways of G protein-coupled receptors and their cross-talk with receptor tyrosine kinases: lessons from bradykinin signaling. Curr Med Chem. 2000;7:911-943.

23. Hackel PO, Gishizky M, Ullrich A. Mig-6 is a negative regulator of the epidermal growth factor receptor signal. Biol Chem. 2001;382:1649-1662.

24. Ostman A, Bohmer FD. Regulation of receptor tyrosine kinase signaling by protein tyrosine phosphatases. Trends Cell Biol. 2001;11:258-266.

25. Mason JM, Morrison DJ, Basson MA, Licht JD. Sprouty proteins: multifaceted negative-feedback regulators of receptor tyrosine kinase signaling. Trends Cell Biol. 2006;16:45-54.

26. Ferby I, Reschke M, Kudlacek $O$, et al. Mig6 is a negative regulator of EGF receptor-mediated skin morphogenesis and tumor formation. Nat Med. 2006;12:568-573.

27. Monnin J, Morand-Villeneuve N, Michel G, Hicks D, VersauxBotteri C. Production of neurospheres from mammalian Muller cells in culture. Neurosci Letters. 2007;421:22-26.

28. Verwaerde P, Tran MA, Montastruc JL, Senard JM, Portolan G. Effects of yohimbine, an alpha 2-adrenoceptor antagonist, on experimental neurogenic orthostatic hypotension. Fundament Clin Pharmacol. 1997;11:567-575.

29. Pawson T, Scott JD. Signaling through scaffold, anchoring, and adaptor proteins. Science. 1997;278:2075-2080.

30. Marshall CJ. Specificity of receptor tyrosine kinase signaling: transient versus sustained extracellular signal-regulated kinase activation. Cell. 1995;80:179-185.

31. Peinado-Ramon P, Wallen A, Hallbook F. MAP kinase phosphatase-1 mRNA is expressed in embryonic sympathetic neurons and is upregulated after NGF stimulation. Brain Res Mol Brain Res. 1998;56:256-267.

32. Jadhav AP, Roesch K, Cepko CL. Development and neurogenic potential of Müller glial cells in the vertebrate retina. Prog Retin Eye Res. 2009;28:249-262.

33. Insua MF, Simon MV, Garelli A, de Los Santos B, Rotstein NP, Politi LE. Trophic factors and neuronal interactions regulate the cell cycle and Pax6 expression in Müller stem cells. $J$ Neurosci Res. 2008;86:1459-1471.
34. Bhatia B, Singhal S, Tadman DN, Khaw PT, Limb GA. SOX2 is required for adult human muller stem cell survival and maintenance of progenicity in vitro. Invest Ophthalmol Vis Sci. 2011;52:136-145.

35. Surzenko N, Crowl T, Bachleda A, Langer L, Pevny L. SOX2 maintains the quiescent progenitor cell state of postnatal retinal Müller glia. Development. 2013;140:1445-1456.

36. Jhaveri DJ, Nanavaty I, Prosper BW, et al. Opposing effects of alpha2- and beta-adrenergic receptor stimulation on quiescent neural precursor cell activity and adult hippocampal neurogenesis. PLoS One. 2014;9:e98736.

37. Yanpallewar SU, Fernandes K, Marathe SV, et al. Alpha2adrenoceptor blockade accelerates the neurogenic, neurotrophic, and behavioral effects of chronic antidepressant treatment. J Neurosci. 2010;30:1096-1109.

38. Schraml E, Fuchs R, Kotzbeck P, Grillari J, Schauenstein K. Acute adrenergic stress inhibits proliferation of murine hematopoietic progenitor cells via p38/MAPK signaling. Stem Cells Dev. 2009;18:215-227.

39. Maier C, Steinberg GK, Sun GH, Zhi GT, Maze M. Neuroprotection by the alpha 2-adrenoreceptor agonist dexmedetomidine in a focal model of cerebral ischemia. Anesthesiology. 1993;79:306-312.

40. Ortin-Martinez A, Valiente-Soriano FJ, Garcia-Ayuso D, et al. A novel in vivo model of focal light emitting diode-induced conephotoreceptor phototoxicity: neuroprotection afforded by brimonidine, BDNF, PEDF or bFGF. PLoS One. 2014;9: e113798.

41. Ozden S, Isenmann S. Neuroprotective properties of different anesthetics on axotomized rat retinal ganglion cells in vivo. $J$ Neurotrauma. 2004;21:73-82.

42. Group TB-AS. Effect of brimonidine $0.5 \%$ on intraocular pressure spikes following $360 \%$ argon laser trabeculoplasty. Ophthalmic Surg Lasers. 1995;26:404-409.

43. Serle JB, Steidl S, Wang RF, Mittag TW, Podos SM. Selective alpha 2-adrenergic agonists B-HT 920 and UK14304-18. Effects on aqueous humor dynamics in monkeys. Arch Ophthalmol. 1991;109:1158-1162.

44. Burke J, Kharlamb A, Shan T, et al. Adrenergic and imidazoline receptor-mediated responses to UK-14, 304-18 (brimonidine) in rabbits and monkeys. A species difference. Ann N Y Acad Sci. 1995;763:78-95.

45. Lafuente MP, Villegas-Perez MP, Mayor S, Aguilera ME, Miralles de Imperial J, Vidal-Sanz M. Neuroprotective effects of brimonidine against transient ischemia-induced retinal ganglion cell death: a dose response in vivo study. Exp Eye Res. 2002;74:181-189.

46. Aktas Z, Gurelik G, Akyurek N, Onol M, Hasanreisoglu B. Neuroprotective effect of topically applied brimonidine tartrate $0.2 \%$ in endothelin-1-induced optic nerve ischaemia model. Clin Exp Ophthalmol. 2007;35:527-534.

47. Ahmed FA, Hegazy K, Chaudhary P, Sharma SC. Neuroprotective effect of alpha(2) agonist (brimonidine) on adult rat retinal ganglion cells after increased intraocular pressure. Brain Res. 2001;913:133-139.

48. Donello JE, Padillo EU, Webster ML, Wheeler LA, Gil DW. alpha(2)-Adrenoceptor agonists inhibit vitreal glutamate and aspartate accumulation and preserve retinal function after transient ischemia.J Pharmacol Exp Ther. 2001;296:216-223.

49. Wheeler LA, Lai R, Woldemussie E. From the lab to the clinic: activation of an alpha-2 agonist pathway is neuroprotective in models of retinal and optic nerve injury. Eur J Ophthalmol. 1999;9(suppl 1):S17-S21. 
50. Danylkova NO, Alcala SR, Pomeranz HD, McLoon LK. Neuroprotective effects of brimonidine treatment in a rodent model of ischemic optic neuropathy. Exp Eye Res. 2007;84: 293-301.

51. Lafuente MP, Lopez-Herrera MP, Mayor-Torroglosa S, Miralles de Imperial J, Villegas-Perez MP, Vidal-Sanz M. Transient ischemia of the retina results in altered retrograde axoplasmic transport: neuroprotection with brimonidine. Exp Neurol. 2002;178:243-258.

52. Mayor-Torroglosa S, De la Villa $P$, Rodriguez ME, et al. Ischemia results 3 months later in altered ERG, degeneration of inner layers, and deafferented tectum: neuroprotection with brimonidine. Invest Ophthalmol Vis Sci. 2005;46:38253835 .
53. Aviles-Trigueros M, Mayor-Torroglosa S, Garcia-Aviles A, et al. Transient ischemia of the retina results in massive degeneration of the retinotectal projection: long-term neuroprotection with brimonidine. Exp Neurol. 2003;184:767-777.

54. Lenkowski JR, Raymond PA. Muller glia: stem cells for generation and regeneration of retinal neurons in teleost fish. Prog Retin Eye Res. 2014;40:94-123.

55. Thanos S, Mey J, Wild M. Treatment of the adult retina with microglia-suppressing factors retards axotomy-induced neuronal degradation and enhances axonal regeneration in vivo and in vitro. $J$ Neurosci. 1993;13:455-466.

56. Fischer AJ, Zelinka C, Milani-Nejad N. Reactive retinal microglia, neuronal survival, and the formation of retinal folds and detachments. Glia. 2015;63:313-327. 